\title{
APPLICATION OF GIS RAPID MAPPING TECHNOLOGY IN DISASTER MONITORING
}

\author{
Wang Zhigang ${ }^{1}$, Tu Jinhua ${ }^{2}$, Liu Guorong ${ }^{2}$, Zhao Qun ${ }^{2}$,* \\ ${ }^{1}$ China Resources Satellite Application Center, Beijing, 100094, China,Kevinwang2000@163.com \\ 2 Landscape architecture of Beijing University of Agriculture, Beijing, 102206, China,869574897@qq.com
}

Commission III, ICWG III/IVa

KEY WORDS: GIS , Rapid Mapping Technology, DEM, Disaster Monitoring, Spatial Distribution, ARCGIS

\begin{abstract}
:
With the rapid development of GIS and RS technology, especially in recent years, GIS technology and its software functions have been increasingly mature and enhanced. And with the rapid development of mathematical statistical tools for spatial modeling and simulation, has promoted the widespread application and popularization of quantization in the field of geology. Based on the investigation of field disaster and the construction of spatial database, this paper uses remote sensing image, DEM and GIS technology to obtain the data information of disaster vulnerability analysis, and makes use of the information model to carry out disaster risk assessment mapping.Using ArcGIS software and its spatial data modeling method, the basic data information of the disaster risk mapping process was acquired and processed, and the spatial data simulation tool was used to map the disaster rapidly.
\end{abstract}

\section{GIS RAPID MAPPING TECHNOLOGY}

\subsection{Developments}

GIS rapid mapping technology is an important support tools for emergency decision-making and emergency rescue at the early stage of a disaster. With the continuous promotion of basic geographic information engineering, the use of existing GIS data to produce thematic maps and general maps will have a wide range of applications. Based on the protection of existing and scientific data, How to effectively utilize existing GIS data and adopt efficient and rapid data processing flow to shorten the production cycle and produce high-quality map products has always been a question that the cartographic community has been exploring.

\subsection{General Instructions}

GIS rapid mapping technology has provided a new software environment for disaster risk assessment data acquisition, data management and processing, spatial analysis, data modeling and simulation and is increasingly becoming an important tool in disaster monitoring.Collect basic contour data elements such as contour lines and contour points, generate DEM raster data, and use related graphic files in GIS databases, such as geomorphologic zoning maps, to form partition templates superimposed on images, or by users through man-machines. The method of interactive interpretation allows the entire remote sensing image to be divided into image sections with different characteristics. Then, they can be supervised or unsupervised separately according to different classification methods or classification criteria, and the results of excessive fragmentation and decentralization can be eliminated during postprocessing, and then they can be spliced together and stored in a GIS database.

\section{GENERATE DISASTER-PRONE DEGREE ZONING MAPS BY GIS RAPID MAPPING TECHNOLOGY}

\subsection{Course of Processing}

Factors that affect the degree of disaster proneness include slope, elevation, rainfall, and other factors. In the disaster information evaluation analysis, the weight of each factor is determined according to the entropy value. The geological disasters are evaluated and analyzed, and then assigned to the data layer according to the weight values of different impact factors; then the layers of each factor are weighted and analyzed. In the zoning analysis of the degree of geological disaster proneness in ArcGIS, the vectorial layers of the influencing factors of various types of geological

* Corresponding author 
disasters are converted into raster data, divided into cell grids, and then according to the grid diagrams of the factors in the cell grid. The layer weight values are used to calculate the degree of geological hazard proneness of each cell grid, and based on this calculated value, the degree of proneness of various types of geological disasters in the cell grid is judged, and the geological disaster susceptibility partition level is divided. Geological disaster susceptibility zones are formed for each type of geological disaster.

\subsection{Generated Image}

Using remote sensing images as the background, the GIS-based rapid data analysis is used to generate disaster susceptibility analysis charts, carry out spatial prediction and zoning mapping of disaster susceptibility levels, and validate zoning results of disaster-prone areas. Using digital methods to carry out disaster-prone zoning maps For the evaluation of the vulnerability of large-scale small-scale area, we use slope unite which is based on the geomorphological analysis to divide it, and then use the statistical data to obtain the geomorphic data such as the gradient and slope direction of the area. This method can obtain high accuracy.

\section{GENERATE DISASTER HAZARD ANALYSIS MAPS BY GIS RAPID MAPPING TECHNOLOGY}

\subsection{Course of Processing}

It uses GIS rapid mapping technology to carry out geological hazard risk assessment, first to set up an object that can accurately express that information or attribute of each factor, can carry out the function operation required by the operator on the base of the object, and then achieve the purpose of quantitative calculation and analysis of each factor. The basic unit of disaster risk assessment is the cell of image. The cell of image carries all the information and attributes of the assessment factor. Therefore, the rationality of cell division directly affects the accuracy of the evaluation results. The division density of cells is influenced by many factors such as the area of the evaluation area and the complexity of the geological environment.

\subsection{Synthetic Image}

Use the layer overlay function in GIS spatial analysis to assess the hazards of geological hazards. Each factor that influences the danger is represented by a layer, and then several factor layers are superposed. Then, the superposed layer contains the information of the original several factor layers. Site sampling points were selected on-site, and their elevation information was measured. After the interpolation algorithm, DEM was formed. And three-dimensional terrain perspective maps were generated by DEM to simulate the field environment, and on this basis to perform threedimensional space analysis, provide a basis for disaster assessment and prediction. Using GIS rapid mapping technology to use disaster risk assessment and methods in disaster hazard areas, we build models based on geological and environmental factors and precipitating factors, carry out risk zone classification, generate hazard maps for hazard areas, divide the divisional levels, and use different colors. It shows the hazard zoning map, analyzes and evaluates the spatial distribution and stability status of the disaster, and divides the study area into different grades of dangerous areas.

\section{GENERATE DIFFERENT LEVELS OF RISK AREA MAPS BY GIS RAPID MAPPING TECHNOLOGY}

\subsection{Method Instructions}

The spatial data analysis function of GIS was used to spatialize and standardize the study area hydrological data, topographic data, social economic data, etc., and the processed data was unified into a grid of a certain resolution size. Using GIS software, the study area is divided into small map spots according to the type of land use. The area of each spot is $500 \mathrm{~m} \times 500 \mathrm{~m}$. Add attribute data for each spot, and edit the attributes of each spot to achieve Statistical analysis of all data in the study area. With grid computing tools, spatial overlay analysis of each indicator. Using ArcGIS tools for the overlay calculation of each factor, the factors need to be digitized, rasterized, and then graded according to the natural fracture grading method.

\subsection{Disaster Assessment}

If it is the risk of disasters, the area will be divided into different levels of risk areas according to the severity and probability of adverse effects of the disaster on life, property, or the environment. Risk zoning can be achieved by qualitative and quantitative methods .If it is a disaster risk, according to the seriousness and probability that the disaster will adversely affect the life, property or environment, the research area will be divided into different risk areas, and Risk zoning can be achieved by qualitative and Quantitative methods.
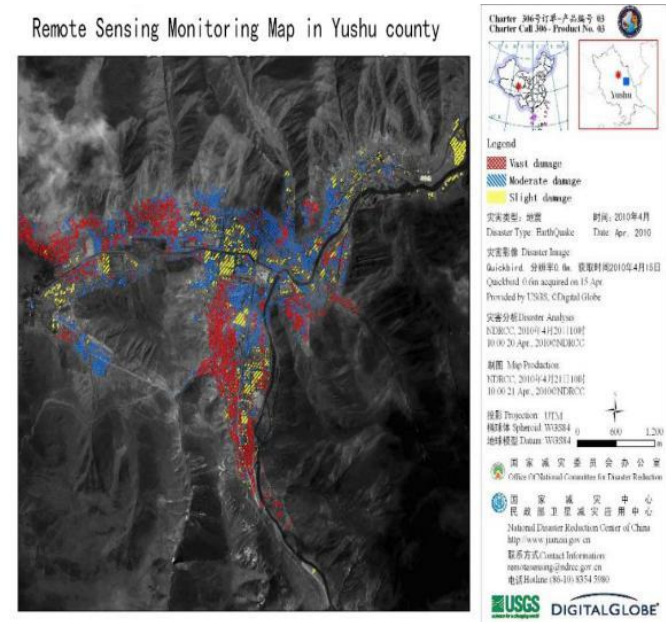
Figure 1: Remote Sensing Monitoring Map in YuShu County

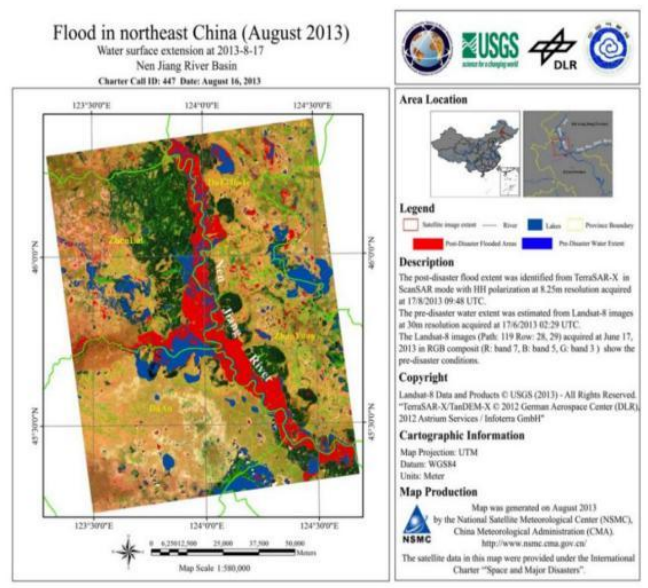

Figure 2: Water surface in Nen Jiang River

\section{CONCLUSION}

GIS rapid mapping technology has been widely used in disaster monitoring. Through the use of GIS rapid mapping technology, the risk assessment system for disaster areas was established, and evaluation indicators were selected. Overlapping analysis of each layer was used to generate a map showing the degree of disaster proneness, an analysis map of hazard areas, and different levels of risk area maps. We laid the foundation for disaster relief and disaster reduction and provided reference for the occurrence, development and evolution of disasters.

\section{REFERENCES}

Lin Jinhuang ,Yu Jinhui , 2017a.Integrated R isk Assessment of Landslide Hazard in Fuzhou Municipality based on the GIS Technique .Subtropical Soil and Water Conservation,29(4),pp.28-32.
Du Juan,He Fei, Shi Peijun, 2006a.Comprehensive risk assessment of flood disaster in xiangiiang river basin. Journal of Natural Disasters, 15(6), pp, 38-54.

Ercanoglu M.,Gokceoglu C.,2004a.Use of fuzzy relations to produce landslide susceptibility map of a landslide prone area West Black Sea Region , Turkey..Engineering Geology, 75(3), pp,229-250.

Zhou Guanhua, Zhuang Wei, Chen Yunhao ,Xi Bin, Jiang Weiguo, Zhou Yucai, Yu Guangwen, 2008a. RS/GIS-based regional evaluation of landslide hazard risk :a case study of GuangChang County, Jiangxi Province. Journal of Natural Disasters, 17(6), pp, 68-72.

Zhou Chenghu ,Wan Qing, Huang Shifeng, 2000a. Study on the risk regionalization of flood disaster based on GIS. Journal of geography, 55(1), pp,1524.

Nandi A.,Shakoor A.,2010a.A GIS-based landslide susceptibility evaluation using bivariate and Multivariate statistical analyses.Engineering geology, 110(1),pp, 11-20

He Ruixiang, Lin Qigen, Wang Ying, etal, 2015a. Factors and high risk are analysis of geological hazards in Yunnan. Journal of Catastrophology, 30(3),pp,208-213.

Wan Shiyun, Li Huahong, Hu juan,2013a.Hazard Zoning of Landslide and Debris Flow Disasters in Yunnan Province. Journal of Catastrophology, 28(2),pp,60-64.

Jin Fuxi, He Hengwu, Xu Zhi, 2015a. Zoning of Geological Hazard Susceptibility Based on GIS.Journal of Institute of Disaster Prevention, 17(4),pp,18-25.

Jiang Xiaobo,Cui Peng,2007a. Hazards Assessmet of Regional Debris Flows Based on GIS. Wuhan University Journal of Natural Sciences, 12(4),pp, 561-656. 